\title{
ResearchArticle
}

\section{An ethnomedicinal approach for the treatment of arthritis}

\author{
Nikhil Agnihotri, Arun Kumar Pandey and Ajay K. Gupta
}

\begin{abstract}
SUMMARY
Arthritis is generally considered as an old age problem but now-a-days it is converted as a gristly health problem, which is widely spread in youths as well as teens. This is a chronic, progressive, disabling autoimmune disease that is commonly responsible for damaging cartilage and bone around the joints. Unfortunately, there is still no effective known medicinal treatment that cures rheumatoid arthritis. Therefore, present research is designed to find some effective alternative treatment of arthritis by some ethno medicinal formulations. The effectiveness of these herbal formulations has been well studied for treatment of arthritis. 90 per cent of the patients of arthritis are cured by these formulations. It is observed that decoction of ashwagandha [Withonia somnifera (L.) Dunal] leaves with methi (Trigonella foenumgracum L.) seeds powder taken 2 to 3 times per day regularly is very effective for the control of arthritic pain. Juice of fresh leaves of mokoi (Solanum nigrum L.) is very effective to cure rheumatic problems. Dried powder or fresh paste of ginger (Zingiber officinalis) is also effective drug for the treatment of arthritis. Root paste of ashwagandha [Withonia somnifera (L.) Dunal] with milk is used in rheumatism, painful swelling and old age problems. Pyaz (Alium cepa L.), Lehsun (Allium sativum L.) Amaltas (Cassia fistula L.) are also effective to treat arthritis. This study encourages the utility of traditional formulations for treating arthritis.
\end{abstract}

Key Words : Arthritis, Autoimmune disease, Ethnomedicine, Traditional formulations

How to cite this article : Agnihotri, Nikhil, Pandey, Arun Kumar and Gupta, Ajay K. (2018). An ethnomedicinal approach for the treatment of arthritis. Internat. J. Plant Sci., 13 (2): 240-244, DOI: 10.15740/HAS/IJPS/13.2/240-244, Copyright@ 2018: Hind Agri-Horticultural Society.

Article chronicle : Received : 25.12.2017; Revised : 12.06.2018; Accepted : 23.06.2018

\section{MEMBERS OF THE RESEARCH FORUM}

Author to be contacted :

Nikhil Agnihotri, Department of Botany, S.K.J.D. P.G. College,

Mangalpur, Kanpur Dehat (Kanpur) India

Email : nikhil.azolla@gmail.com

Address of the Co-authors:

Arun Kumar Pandey, Major S.D. Singh P.G. Ayurvedic Medical College, Baikunthpuri, Fatehgarh, Farrukhabad (U.P.) India

Ajay K. Gupta, University Institute of Pharmacy, C.S.J.M. University, Kanpur (U.P.) India 